\title{
Correction to: The HF-rating as a universal complement to the $h$-index
}

\section{Yves Fassin ${ }^{1}$}

Published online: 30 October 2020

๑) Akadémiai Kiadó, Budapest, Hungary 2020

\section{Correction to: Scientometrics} https://doi.org/10.1007/s11192-020-03611-5

In the original publication of the article, the author name was published incorrect. The correct name is given with this Correction.

The original article has been corrected. 